\title{
Awareness regarding Regular Eye check up among Diabetes Patients attending a Tertiary Care Hospital
}

\author{
Dr. Viswamithra $\mathrm{P}^{1}$ \& Dr. Krishnaveni Avvaru ${ }^{2}$ \\ ${ }^{1}$ Associate Professor of Ophthalmology, ${ }^{2}$ Professor of Community Medicine Andhra Medical College, \\ Visakhapatnam
}

\begin{abstract}
:
Background: Diabetic retinopathy is the commonest complication of diabetes. In India, prevalence of diabetic retinopathy varies from $16.6 \%$ to $26.8 \%$. About $10 \%$ of diabetics at any point of time will have vision threatening retinopathy requiring specialist ophthalmological management. Aim: To study the awareness regarding the necessity of regular eye check up among the diabetic patients. Methodology: A total of 105 patients attending diabetes clinic in a tertiary care hospital were included. A pretested, semi structured questionnaire was administered. Study variables include age, gender, literacy status, occupation, family history of diabetes, awareness regarding diabetes etc. Results: The age group of the study population ranged from 22 years to 74 years with mean age of 55.43 years. Only $37.14 \%$ of diabetics were aware of the necessity of regular eye checkups. Only 6 males and 3 female diabetic patients were having regular eye check up. Awareness of regular eye check up was more among those who have diabetes for $>5$ years duration and those who had family history of Diabetes. It was also observed that awareness regarding eye check up was increasing with increase in educational status. Conclusion: Our results suggest that awareness regarding eye check up among diabetic patients is very poor. Delivering ophthalmic care to diabetic patients at appropriate time can reduce the suffering caused by visual impairement and blindness.
\end{abstract}

Key Words: Awareness of eye checkups, Diabetes, Ophthalmic care

\section{Introduction}

Diabetes is the most common metabolic disorder in the world. According to Diabetes Atlas 2013 released by the International diabetes federation, 382 million people in the world are living with diabetes. This number is expected to increase to 592 million by the year $2035 .{ }^{1}$ Diabetic retinopathy is the commonest complication of diabetes. ${ }^{2}$ About $10 \%$ of diabetics at any point of time will have vision threatening retinopathy requiring specialist ophthalmological management. In India, prevalence of diabetic retinopathy varies from $16.6 \%$ to $26.8 \%$.Risk factors for the onset and progression of diabetic retinopathy include duration of diabetes , degree of control of hyperglycemia, hypertension, presence of renal disease, pregnancy etc. ${ }^{3}$

Diabetic retinopathy can be divided into Non Proliferative and Proliferative stages. Non proliferative diabetic retinopathy, an early stage of diabetic retinopathy, is characterised by the presence of retinal microaneurysms, intra retinal haemorrhages and hard exudates. Proliferative diabetic retinopathy is characterised by the development of neovascularization. These new vessels bleed very easily causing vitreous haemorrhage and retinal haemorrhage. This massive haemorrhage is the cause for sudden, painless loss of vision in patients with diabetic retinopathy. Gradually, fibrovascular proliferation occurs following haemorrhages. These fibrovacular bands contract,causing tractional retinal detachment. This is the common cause for gradual ,progressive loss of vision in diabetic patients. Diabetic retinopathy is always bilateral.It is the leading cause of bilateral blindness in the working class. ${ }^{4}$

In the early stages of diabetic retinopathy, patients are usually asymptomatic. In the more advanced stage of the disease, patients may have symptoms like floaters, blurred vision, distorted vision or progressive loss of vision. Sometimes, diabetic retinopathy changes occur so subtly, even at the advanced stage of retinopathy, patient may not be having any visual symptoms till the sudden fall of vision .Hence, in diabetics, it is mandatory to have a regular, life long evaluation of the eyes by a qualified ophthalmologist for the detection of diabetic retinopathy changes which may benefit from early treatment thus saving the patient from permanent blindness. $^{5}$

Hence, an attempt was made to study the awareness regarding the necessity of regular eye check up among the diabetic patients.

\section{Methodology}

A hospital based, cross sectional study was conducted among diabetic patients. A total of 105 patients attending diabetes clinic in King George Hospital, Visakhapatnam were included in the study. Informed consent was taken after explaining the purpose of the study and those who were willing to participate in the study were 
included. A pretested, semi structured questionnaire was administered. Study variables include age, gender, literacy status, occupation, family history of diabetes, awareness regarding diabetes etc. Data was analysed using MS Excel spread sheet and relevant statistical tests were applied and $\mathrm{p}<0.05 \%$ was considered statistically significant.

\section{Results}

Out of 105 diabetic patients who were included in the study, 61 were males and 44 were females. The age group of the study population ranged from 22 years to 74 years with mean age of 55.43 years. Majority (38.09\%) were in the age group of 51-60 years, followed by $61-70$ years(34.28\%).

Regarding literacy rates, $27.6 \%$ had high school education and $10.47 \%$ were post graduates. Nearly half of our study participants $(48.57 \%)$ gave family history of diabetes. Nearly $3 / 4^{\text {th }}(76.10 \%)$ of study participants were having diabetes for more than 5 years duration.

When the question "are you aware of the necessity of regular eye check up ?" was asked only $37.14 \%$ gave positive response. Among them, consulting doctor was the source of information for only 21 participants. In our study, only 6 males and 3 female diabetic patients were having regular eye check up.

It was observed that, majority (69\%) of the participants who were having awareness regarding regular eye check up, had family history of diabetes and this association was found to be statistically significant $(\mathrm{Z}=3.47, \mathrm{p}<0.05)$. It was also found that awareness of regular eye check up was more among those who have diabetes for $>5$ years duration. On further analysis, it was also observed that awareness regarding eye check ups was increasing with increase in educational status (as shown in Table 8)

\section{Discussion}

In our study, awareness regarding the necessity for regular eye check up was very poor (37.14\%). Awareness rates were better among those who had family history of diabetes and in those who have diabetes for more than 5 years. It was also observed that education status was also associated with increase in awareness levels regarding eye check up. Source of information was " consulting doctor" in $1 / 5^{\text {th }}$ of our participants and even other sources such as media didn't play any significant role. This finding is in concurrence with a similar study done by I. Mohammed et al in Nigeria. ${ }^{6}$

\section{Conclusion}

Our results suggest that awareness regarding eye check up among diabetic patients is very poor. Delivering ophthalmic care to diabetic patients at appropriate time can reduce the suffering caused by visual impairement and blindness. Hence there is an urgent need for health education regarding the necessity for regular eye check up among diabetes patients as well as health care providers.

\section{Bibliography}

[1]. Anjana RM,Pradeepa R,Deepa M, Dutta M,Unnikrishnan R et al. "Prevalence of diabetes and pre diabetes in urban and rural India:phase 1 result of the Indian Council of Medical Research -India Diabetes (ICMR-INDIAB) study" Diabetologica 54.12 (2011): NCBI.web.march 2013.

[2]. KleinR.Klein BE,Moss SE. Visual impairement in diabetes. Ophthalmology 1984;91:1-9

[3]. Macky TA,Khater N,Al-Zamil MA et al.Epidemiology of diabetic retinopathyin Egypt:A hospital based study. Ophthalmic res 2011:45:73-8

[4]. WHO: Global burden of diabetes:Press release WHO/63:WorldHealthOrganisation;Sept 1998

[5]. Verma L,Elankumaran P,Prakash G,Venkatesh P,Tewari HK. Awareness of diabetic retinopathy among diabetics. Indian journal of ophthalmology 2002;50:355

[6]. I Mohammed, AM Waziri.Awareness of diabetic retinopathy among diabetic patients at the murtala mohammed hospital,Kano, Nigeria. Nigerian Medical Journal 2009;50:38-41

TABLES

TABLE No.1: Distribution of study population according to age groups

\begin{tabular}{|l|l|l|l|}
\hline Age group in years & Males & Females & Total \\
\hline $21-30$ & 1 & 1 & $\mathbf{2}$ \\
\hline $31-40$ & 3 & 1 & $\mathbf{4}$ \\
\hline $41-50$ & 7 & 8 & $\mathbf{1 5}$ \\
\hline $51-60$ & 24 & 16 & $\mathbf{4 0}$ \\
\hline $61-70$ & 19 & 17 & $\mathbf{3 6}$ \\
\hline$>70$ & 7 & 1 & $\mathbf{8}$ \\
\hline Total & $\mathbf{6 1}$ & $\mathbf{4 4}$ & $\mathbf{1 0 5}$ \\
\hline
\end{tabular}


TABLE No.2: Distribution of study population according to educational status

\begin{tabular}{|l|l|l|l|}
\hline Educational status & Males & Females & Total \\
\hline Illiterate & 4 & 10 & $\mathbf{1 4}$ \\
\hline Elementary school & 0 & 11 & $\mathbf{1 1}$ \\
\hline High school & 17 & 12 & $\mathbf{2 9}$ \\
\hline Under graduation & 9 & 2 & $\mathbf{1 1}$ \\
\hline Graduation & 23 & 6 & $\mathbf{2 9}$ \\
\hline Post graduation & 8 & 3 & $\mathbf{1 1}$ \\
\hline Total & $\mathbf{6 1}$ & $\mathbf{4 4}$ & $\mathbf{1 0 5}$ \\
\hline
\end{tabular}

TABLE No.3: Distribution of study population according to occupation

\begin{tabular}{|l|l|l|l|}
\hline Occupation & Males & Females & Total \\
\hline Unemployed & 1 & 27 & $\mathbf{2 8}$ \\
\hline Unskilled & 5 & 9 & $\mathbf{1 4}$ \\
\hline Semi skilled & 44 & 4 & $\mathbf{4 8}$ \\
\hline Skilled & 11 & 4 & $\mathbf{1 5}$ \\
\hline Total & $\mathbf{6 1}$ & $\mathbf{4 4}$ & $\mathbf{1 0 5}$ \\
\hline
\end{tabular}

TABLE No.4: Distribution of study population according to family history of Diabetes

\begin{tabular}{|l|l|l|l|}
\hline Family H/O DM & Males & Females & Total \\
\hline Present & 24 & 27 & $\mathbf{5 1}$ \\
\hline Absent & 37 & 17 & $\mathbf{5 4}$ \\
\hline Total & $\mathbf{6 1}$ & $\mathbf{4 4}$ & $\mathbf{1 0 5}$ \\
\hline
\end{tabular}

TABLE No.5: Distribution of study population according to duration of Diabetes

\begin{tabular}{|l|l|l|l|}
\hline Duration of DM & Males & Females & Total \\
\hline$<5 \mathrm{yrs}$ & 16 & 9 & $\mathbf{2 5}$ \\
\hline$>5 \mathrm{yrs}$ & 45 & 35 & $\mathbf{8 0}$ \\
\hline Total & $\mathbf{6 1}$ & $\mathbf{4 4}$ & $\mathbf{1 0 5}$ \\
\hline
\end{tabular}

TABLE No.6: Distribution of study population according to awareness on eye check up

\begin{tabular}{|l|l|l|l|}
\hline Awareness & Males & Females & Total \\
\hline Present & 28 & 11 & $\mathbf{3 9}$ \\
\hline Absent & 33 & 33 & $\mathbf{6 6}$ \\
\hline Total & $\mathbf{6 1}$ & $\mathbf{4 4}$ & $\mathbf{1 0 5}$ \\
\hline
\end{tabular}

TABLE No.7: Distribution of study population according to source of information regarding eye check

\begin{tabular}{|l|l|l|l|}
\hline Source of information & Males & Females & Total \\
\hline Doctor & 16 & 5 & $\mathbf{2 1}$ \\
\hline Media & 12 & 6 & $\mathbf{1 8}$ \\
\hline Total & $\mathbf{2 8}$ & $\mathbf{1 1}$ & $\mathbf{3 9}$ \\
\hline
\end{tabular}

TABLE No.8: Distribution of study population according to educational status in persons with awareness regarding eye check up

\begin{tabular}{|l|l|}
\hline Educational status & Total \\
\hline Illiterate & 1 \\
\hline Elementary school & 1 \\
\hline High school & 4 \\
\hline Under graduation & 4 \\
\hline Graduation & 18 \\
\hline Post graduation & 11 \\
\hline Total & $\mathbf{3 9}$ \\
\hline
\end{tabular}

TABLE No.9: Distribution of study population according to duration and family history of Diabetes in persons with awareness regarding eye check up

\begin{tabular}{|l|l|}
\hline Duration of Diabetes & $\begin{array}{l}\text { No of } \\
\text { patients }(\mathbf{n}=\mathbf{3 9})\end{array}$ \\
\hline$<5$ yrs & 11 \\
\hline$>5$ yrs & 28 \\
\hline Family history of Diabetes & \\
\hline PRESENT & 27 \\
\hline ABSENT & 12 \\
\hline
\end{tabular}

